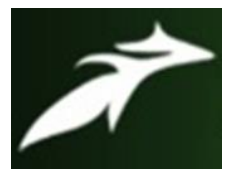

Gadona Enoch Alhamdu et al, International Journal of Advances in Agricultural Science and Technology,

Vol.7 Issue.11, November-2020, pg. 112-122

ISSN: 2348-1358

Impact Factor: 6.057

NAAS Rating: 3.77

\title{
LAND USE LAND COVER ANALYSIS OF DEGRADED AREAS IN MUBI-NORTH AND GOMBI LOCAL GOVERNMENT AREAS OF ADAMAWA STATE: NIGERIA
}

\author{
Gadona Enoch Alhamdu'; Gamaniel Japheth²; Elisha Tizhe Faive ${ }^{3}$ \\ Department of Surveying and Geoinformatics, Federal Polytechnic, Mubi, Adamawa State, Nigeria \\ DOI: 10.47856/ijaast.2020.v07i11.015
}

\begin{abstract}
The research study examines the use of Remote Sensing and GIS in mapping Land use Land cover in Mubi/North and Gombi Local government areas between 1986, 1996, 2006 and 2016 so as to detect the changes that has taken place in this status between these periods. Attempt was made at projecting the Land use Land cover and the Normalized Difference Vegetation Index (NDVI) for the past thirty years (30yr) and relating the analyses to Land degradation. The result of the work showed a rapid growth in built up areas between the year 1986 to 2016, while between 1986 to 2006 witness reduction in water surface areas and thus an increase in bare surface areas. The NDVI for same period shows the level of depletion of vegetation cover. Thus land is being degraded. Suggestions were therefore made at the end of the study to use the information as contained therein for sustainable Land management
\end{abstract}

Keywords: Remote Sensing, Land use Land cover, Normalized Difference Vegetation Index.

\section{Introduction}

The millennium development goals have made substantial progress to achieve their set objectives, however, hunger, poverty and food insecurity persist, because the key ecosystems that underpin and service the natural resource base continue to be depleted and degraded. Land degradation has become a global phenomenon and is currently threatening the ecosystem which is mainly caused by climate changes and human influence (Farooq, Fatima and Kashif, 2014). According to the United Nations Convention to Combat Degradation (UNCCD), Land degradation is the reduction or loss in arid, semi-arid and dry sub-humid areas, of the biological or economic productivity and complexity of rain fed crop land and wood lands resulting from land uses or from a process or combination of process, including processes arising from human activities and habitation patterns.

Land degradation is caused by a variety of complex interrelated degradation process, these include: 1) soil degradation 11) vegetation degradation, 111) water resource degradation and 1V) soil or water pollution Ann (2002). 


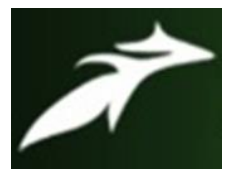

Gadona Enoch Alhamdu et al, International Journal of Advances in Agricultural Science and Technology, Vol.7 Issue.11, November-2020, pg. 112-122

ISSN: 2348-1358

Impact Factor: 6.057

NAAS Rating: 3.77

Remote sensing data and Geographical Information System (GIS) tools can offer unbiased view of large areas, with spatially explicit information distribution and time repetition and has thus been widely used to monitor land degradation, pattern and change detection at regional scale Farooq (2013).

Base on various research studies carried out in Adamawa State, there is that death of information between land cover types and natural phenomenon such as rainfall and other climatic conditions. While this information exists, on the presence of anthropogenic activities, main drivers of land degradation and the underlying factors that drive this degradation are lucking. These lacks of information implies that whatever program put in place for sustainable use of resources in Adamawa state would not yield the desired result. Hence this research study is aimed at analyzing land use land cover mapping of degraded areas in Mubi/North and Gombi local governments of Adamawa state using satellite imageries of 1986, 1996, 2006 and 2016.

The research would address some of the main land use/ land cover features from 1986 to 2016 time period and would examine what changes that have occurred in land use/ land cover(LULC) within the period of the study and how the growth in population affects the vegetation and agricultural lands. Knowledge of the spatial distribution of LULC is relevant as to know the availability of resource base as such they become a significant basis for planners in drafting and implementing developmental plan for sustainable use of land resources as well as for resource restoratration and quality enhancement.

The research study covers two local government areas in the northern part of Adamawa state, Mubi/North and Gombi. The study would identify and map the LULC changes from satellite imageries of 1986, 1996, 2006 and 2016 time period. The temporal and spatial data of these satellite imageries were analyzed to determine the extent and changes in land cover types and the extent of these changes.

An important application of remote sensing is the generation of LULC maps from satellite imagery, compared to the traditional mapping approach such as terrestrial survey and basic aerial photo-interpretation, land use mapping using satellite imagery has the advantage of low cost, large area coverage, repetitively and computer compatible Million (2002) consequently, the end products of land use study obtain from satellite imagery such as land use maps and Geographical Information System (GIS) layer have become an essential tool in many operational research studies involving land resource management.( Parakasam, 2010) carried out study of Kodiak anal Tuluk, in India using remote sensing and GIS approach. Landsat imageries of 2003, 2008 and Tuluk map of 1961 were used. In similar studies (Srumanta and Moupriya, 2012) carried out 


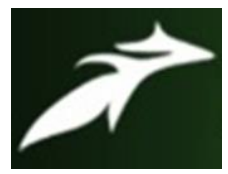

Gadona Enoch Alhamdu et al, International Journal of Advances in Agricultural Science and Technology, Vol.7 Issue.11, November-2020, pg. 112-122

ISSN: 2348-1358

Impact Factor: 6.057

NAAS Rating: 3.77

LULC studies of Bundwan municipality in India.in both studies, results obtained showed rapid growth of industrial sector, expansion of urban centers where cultivated lands were converted into settlement areas; existing ponds were filled for purpose of residential development, vegetation and forested areas were decreasing for settlement and agricultural purpose.

LULC can be classified using gradable classification method; this approach improves the accuracy of classification when identifying LULC. The method recognize small objects by considering the spatial features of lulc and boundary problems between features in an environment can be classified using the gradable classification approach ( Keigo and Koarar, 2012 ). Unfortunately, there is general lack of accurate LULC maps in Nigeria ( Ndukwe, 1997, Ezeomedo, 2006, Innocent and Joel 2013 ) also observed that the application of remote sensing data and geographical information system (GIS) is mostly in image analysis, mapping, monitoring of urban land use. It is also applied to estimate various surface features and provide LULC information for planning.

\section{The Study Areas}

Mubi/North and Gombi Local government areas of Adamawa State constitute the study area and are located in the Northeast Nigeria between latitudes $10^{\circ} 04^{\prime} 00^{\mathrm{n}} \mathrm{N}-10^{\circ} 14^{\prime} 15^{\prime \prime} \mathrm{N}$ and longitudes $13^{\circ} 40^{\prime} 30^{\prime \prime} \mathrm{E}-13^{0} 34^{\prime} 15^{\prime \prime} \mathrm{E}$ of the Greenwich meridian and for Gombi $10^{\circ} 5^{\prime} 15^{\prime \prime} \mathrm{N}-10^{0} 15^{\prime} 30^{\prime \prime} \mathrm{N}$ and longitudes $13^{\circ} 30^{\prime} 15^{\prime \prime} \mathrm{E}-13^{\circ} 30^{\prime} 45^{\prime \prime} \mathrm{E}$ of the Greenwich meridian. Gombi covers an area of about 2,232.03 $\mathrm{km}_{2}$ Mubi/North covers an area of about $495.64 \mathrm{~km}_{2}$ the area is borded to the south by Song and to the north by Borno state. The area is further borded to the east by Mubi/North. Mubi/North is borded to the south by Maiha and Mubi/South, the area is borded to the north by Michika and to the east by Cameroun Republic. 


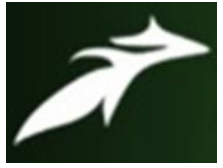

Gadona Enoch Alhamdu et al, International Journal of Advances in Agricultural Science and Technology,

Vol.7 Issue.11, November-2020, pg. 112-122

ISSN: 2348-1358

Impact Factor: 6.057

NAAS Rating: 3.77

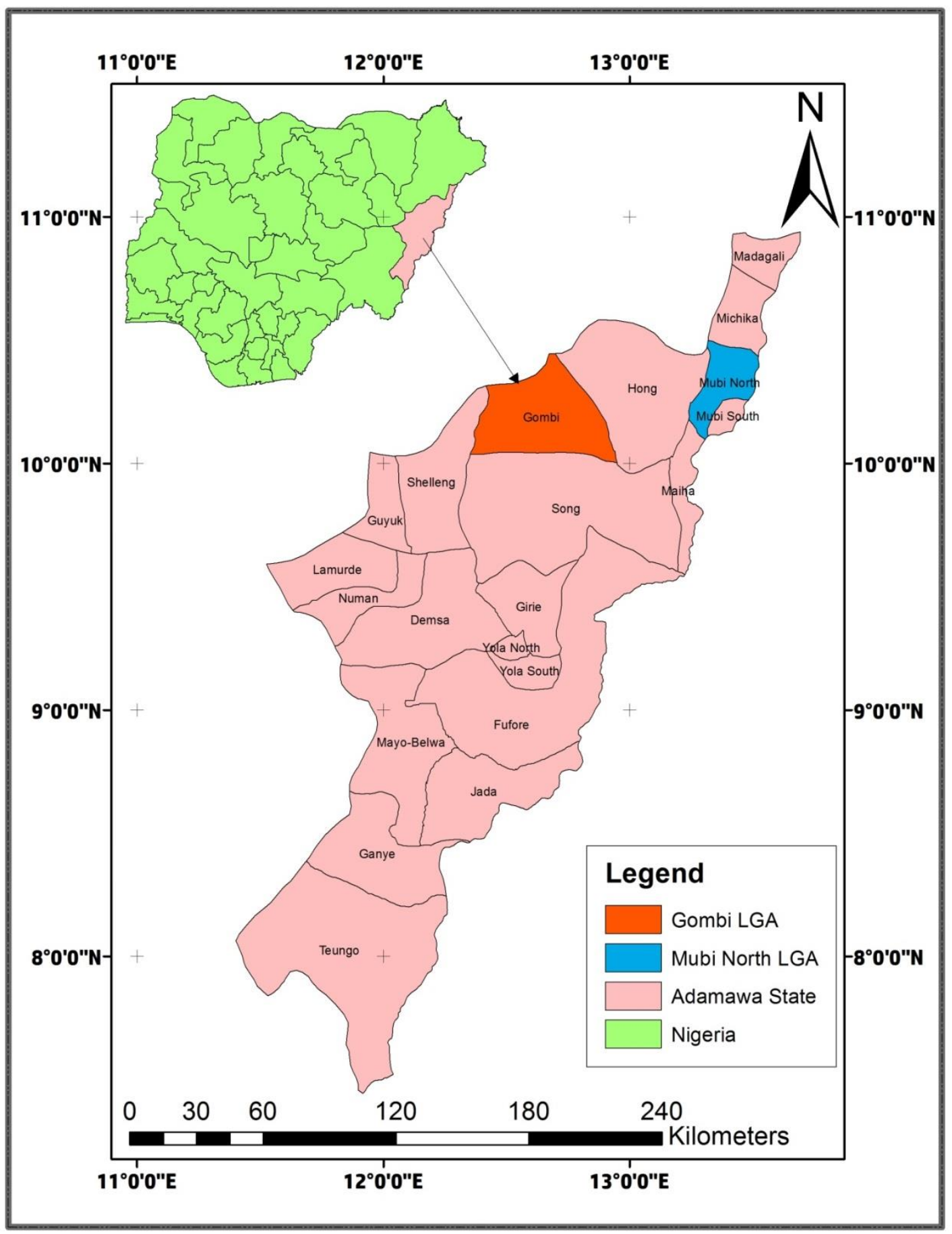

Figure 1A: Map of Adamawa State showing the Study Area. 


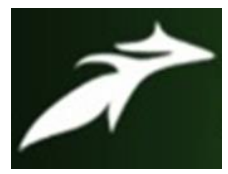

Gadona Enoch Alhamdu et al, International Journal of Advances in Agricultural Science and Technology,

Vol.7 Issue.11, November-2020, pg. 112-122

ISSN: 2348-1358

Impact Factor: 6.057

NAAS Rating: 3.77

\section{Methodology}

Data on land use and land cover for four time period using Landsat Thematic Mapper (TM) of 1986, 1996, 2006 and 2016 with 30m resolution was downloaded from Earth Explorer (w.w.w.earthexplorer.usg.govt.). Landsat ETM (Enhanced Thematic Mapper) with 30m resolution covering Mubi/North and Gombi local government areas was used. The software used includes, Integrated Land and Water Information System (ILWIS) version 3.1, ArcGIS 10.3, Erdas Imagine was used to perform image classification using maximum likelihood algorithm. The image processing /data preparation and analysis was carried out using ILWIS 3.1, ArcGIS 10.3 and Erdas imagine 2014 software packages.

The downloaded satellite images, sub-setting was carried out to the area of interest from the larger data. The sub-setting of the imageries was done for the two local government areas of study. Images were first imported into Erdas imageries band by band from TIF format, later they were layer stocked, Area of Interest (AOI) were sub-sated from the main sense each of the data set was classified into various LULC types. The supervised classification was adopted using training sets, constructed through ground trothing (Castellin, Elvalga, li and Turk, 1998) This classification was based on maximum likelihood classifier (MLC) algorithm (Erdas Field Guide, 1997) this classification assumes that a pixel has certain probability of belonging to a particular class, these probability are equal for all classes and the input data in each band follows the Gaussian distribution function (Lillesand and Kiefer, 2004). The supervised image classification was used to classify the images in five (5) land cover classes using the maximum likelihood parametric rule of Erdas Imagine 2004. The Raster/Supervise/Supervised sub-routine was activated to classify the images into five classes; Agricultural lands, Vegetation cover, urban areas, bare surface areas and Water surface areas.

Accuracy assessment is the most important step in evaluating the different image processing routines in image classification (FAO, 2002, IN Lu and Weng, 2005). The accuracy of the classification in this study was checked with stratified random sampling methods for each image. 


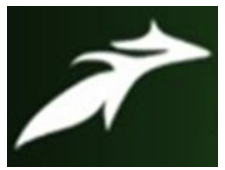

Gadona Enoch Alhamdu et al, International Journal of Advances in Agricultural Science and Technology,

Vol.7 Issue.11, November-2020, pg. 112-122

ISSN: 2348-1358

Impact Factor: 6.057

NAAS Rating: 3.77

\section{Results and Discussion}

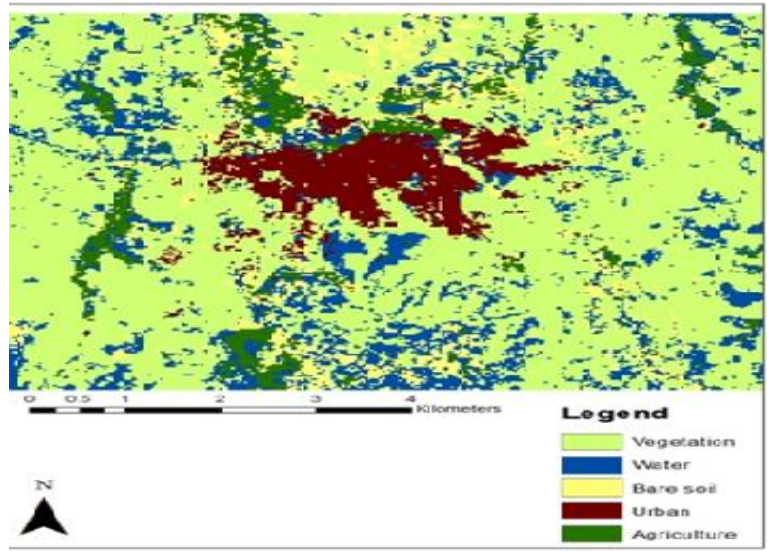

Figure.1: Land Use Land Cover of Mubi North 1986

Source: Landsat ETM downloaded from Earth Explorer

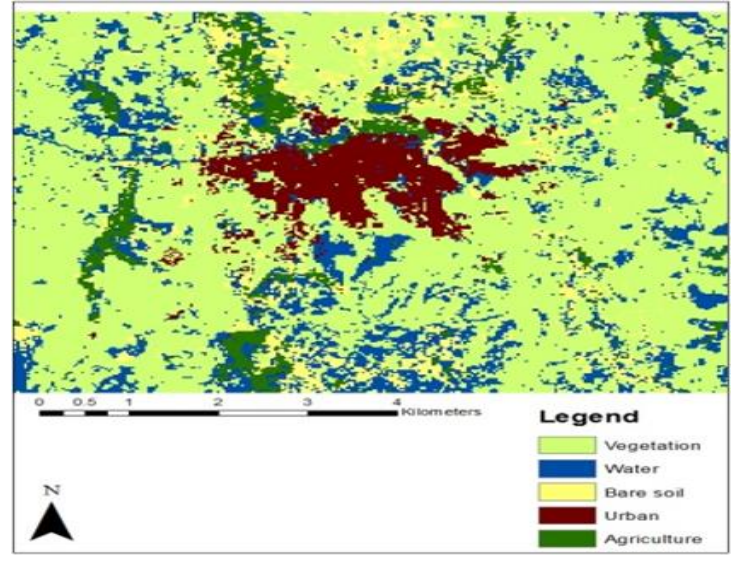

Figure .2: Land Use Land Cover of Mubi North 1996

Source: Landsat ETM downloaded from Earth Explorer

Figures 1 and .2 shows the land use land cover classification of Mubi/North for 1986 and 1996.The land use land cover were classified into five different land cover classes, vegetation, agricultural lands, urban areas, water surface and bare surface areas.

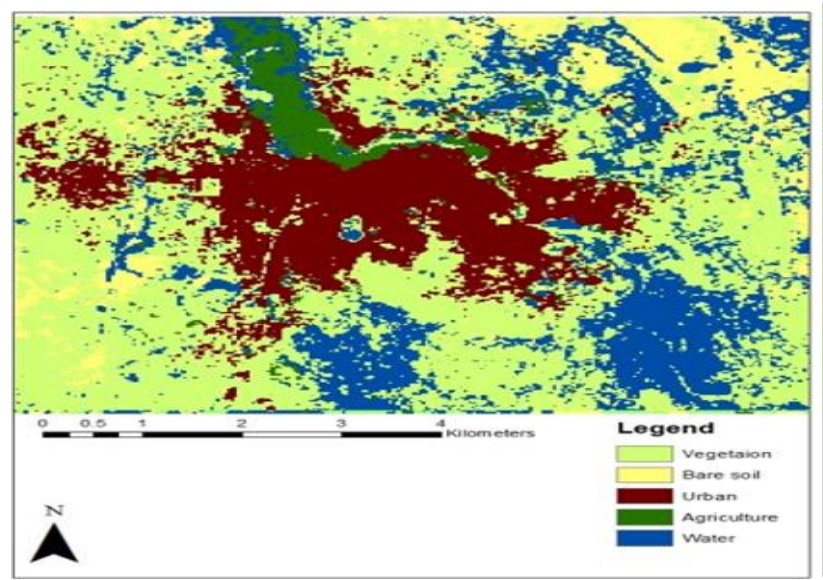

Figure .3: Land Use Land Cover of Mubi North 2006

Source: Landsat ETM downloaded from Earth Explorer

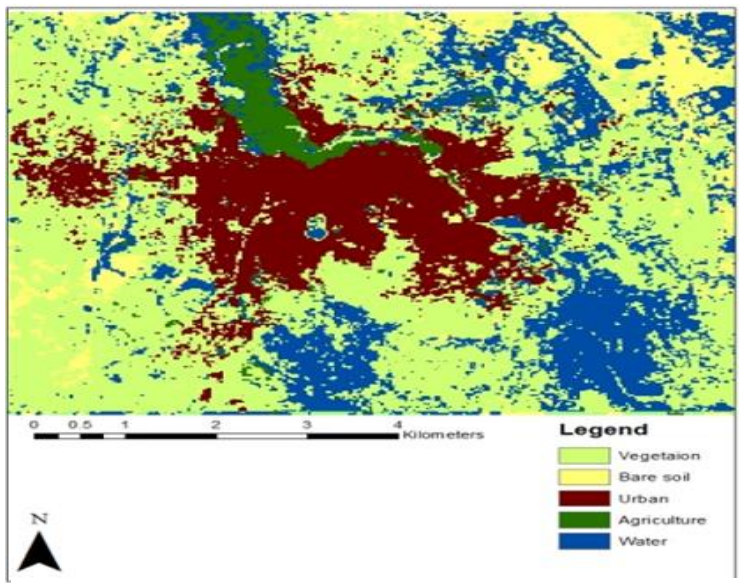

Figure .4: Land Use Land Cover of Mubi North 2016

Source: Landsat ETM downloaded from Earth Explorer 


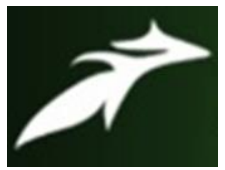

Gadona Enoch Alhamdu et al, International Journal of Advances in Agricultural Science and Technology,

Vol.7 Issue.11, November-2020, pg. 112-122

ISSN: 2348-1358

Impact Factor: 6.057

NAAS Rating: 3.77

Figures .3 and .4 shows the land use land cover classification of Mubi/North for 2006 and 2016s.The land use land cover were classified into five different land cover classes, vegetation,agricultural lands, urban areas, water surface and bare surface areas.

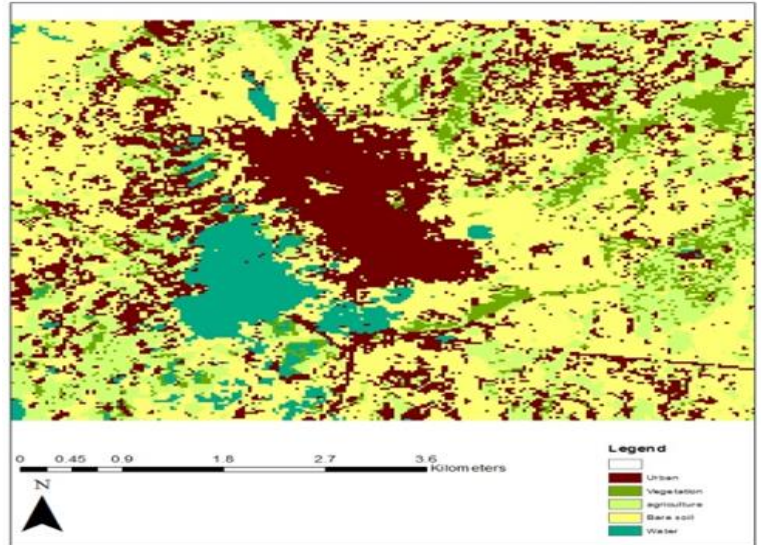

Figure.5: Land Use Land Cover of Gombi 1986 Source: Landsat ETM downloaded from Earth Explorer

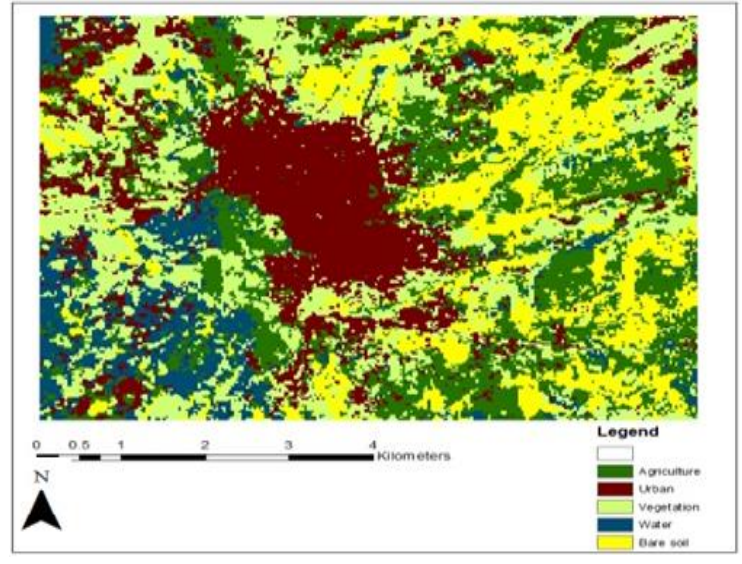

Figure6: Land Use Land Cover of Gombi 1996 Source: Landsat ETM downloaded from Earth Explorer

Figures 5 and 6 shows the land use land cover classification of Gombi for 1986 and 1996.The land use land cover were classified into five different land cover classes, vegetation,agricultural lands, urban areas, water surface and bare surface areas.

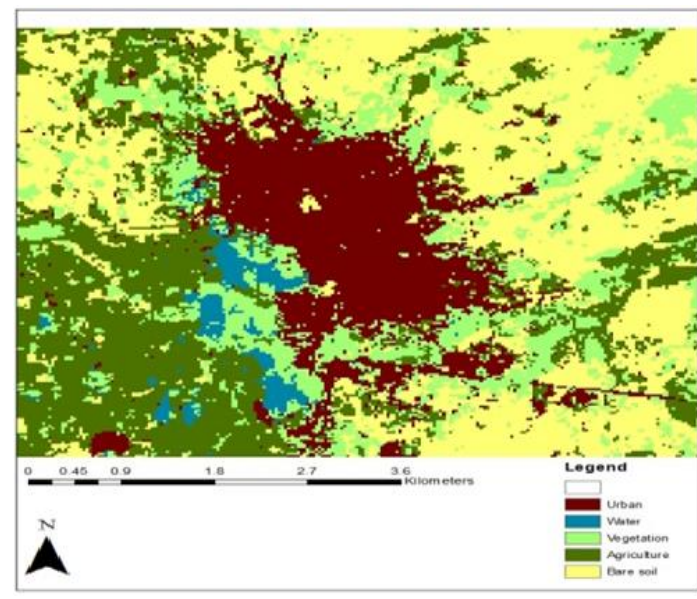

Figure7: Land Use Land Cover of Gombi 2006

Source: Landsat ETM downloaded from Earth Explorer

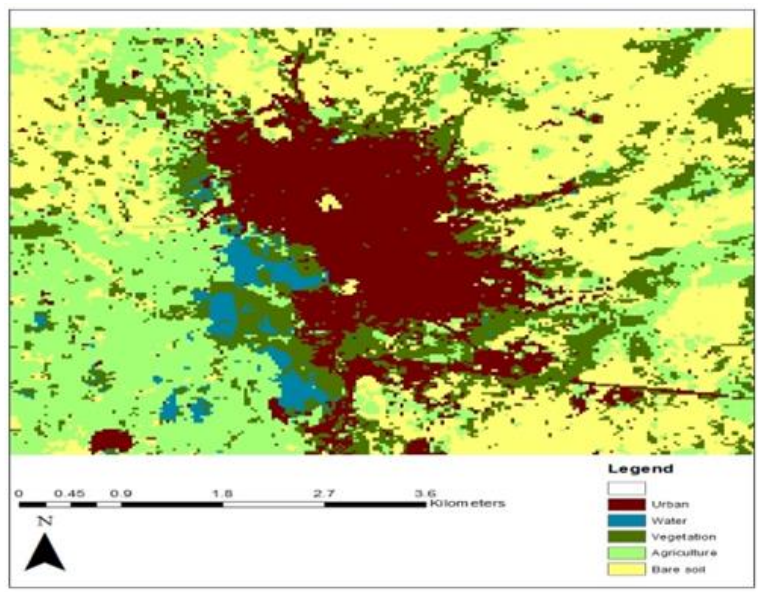

Figure.8: Land Use Land Cover of Gombi 2016 Source: Landsat ETM downloaded from Earth Explorer 


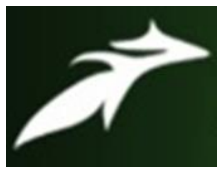

Gadona Enoch Alhamdu et al, International Journal of Advances in Agricultural Science and Technology,

Vol.7 Issue.11, November-2020, pg. 112-122

ISSN: 2348-1358

Impact Factor: 6.057

NAAS Rating: 3.77

Figures 7 and.8 shows the land use land cover classification of Gombi for 2006 and 2016.The land use land cover were classified into five different land cover classes, vegetation,agricultural lands, urban areas, water surface and bare surface areas.

Table 1: Extend of Area Coverage in Square Kilometers, Mubi/North \& Gombi.

\begin{tabular}{lllllll}
\hline $\begin{array}{l}\text { Period } \\
\text { Mubi/N }\end{array}$ & $\begin{array}{l}\text { Total } \\
\text { land Area }\end{array}$ & Agriculture & Vegetation & $\begin{array}{l}\text { Urban } \\
\text { Area }\end{array}$ & Bare Soil & $\begin{array}{l}\text { Water } \\
\text { surface. }\end{array}$ \\
\hline 1986 & 67,212 & 3836 & 40245 & 4485 & 7026 & 11620 \\
1996 & 67212 & 3688 & 40245 & 4483 & 7026 & 11620 \\
2006 & 67,212 & 3179 & 33123 & 9593 & 10876 & 10441 \\
2016 & 67,212 & 4637 & 50238 & 40309 & 27501 & 12651 \\
Period & Land & Agriculture & Vegetation & Urban & Bare Soil & Water \\
Gombi & Area & & & Area & & Surface \\
1986 & 39,797 & 11979 & 13418 & 2375 & 2148 & 5644 \\
1996 & 39,797 & 5344 & 14137 & 5589 & 10137 & 4590 \\
2006 & 39,797 & 9471 & 910 & 9867 & 18991 & 558 \\
2016 & 39,797 & 5344 & 10968 & 11861 & 10134 & 1490 \\
\hline
\end{tabular}

\section{Mubi/North Local Government}

Five land use classes were identified and studied, Agriculture, Vegetation, Urban surface, bare soil and Water surface. The land use classes were for 1986, 1996, 2006 and 2016

Agriculture showed an increase between the years 1996 to 2006 by $3.686 \mathrm{sq} \mathrm{kilm}$. And between 2006 to 2016 showed an increase of $5,440 \mathrm{sqkm}$

Vegetation cover, decrease between 1996 and 2006 by 7,104sqkm while there was an increase in vegetation cover between 2006 and 2016 by 97,215sqkm 


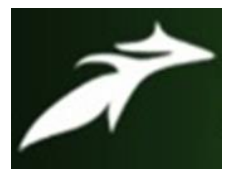

Gadona Enoch Alhamdu et al, International Journal of Advances in Agricultural Science and Technology, Vol.7 Issue.11, November-2020, pg. 112-122

ISSN: 2348-1358

Impact Factor: 6.057

NAAS Rating: 3.77

Urban area increase between 1996 and 2006 by 5,128sqkm and continue to increase in 2016 by $39,191 \mathrm{sqkm}$

Bare surface areas increased from 1996 to 2006 by 3,868sqkm and continue to increase by $16,607 \mathrm{sqkm}$.

Water surface area decrease between 1996 to 2006 by 348sqkm and increase in 2016 by 41,690sqkm..

\section{Gombi Local Government}

Five land use classes were identified and studied Agriculture, Vegetation, Urban surface, bare soil. And Water surface for 1986.1996.2006, and 2016. In 1986 the total land area was 35,564sqkm. Agriculture decline between 1986 to 1996 by 6,635sqkm and increased from 1996 to 2006 by $6,635 \mathrm{sqkm}$. and decrease again between 2006 to 2016 by $6,635 \mathrm{sqkm}$.

Vegetation cover increase between 1986 and 1996 by 719sqkm and decline in 2006 by 10,719 sqkm and increase in 2016 by 30,719 sqkm

Urban area, increase between 1986 and 1996 by 3,214sqkm, between 1996 and 2006 continue to rise by $6,785 \mathrm{sqkm}$ and decline in 2016 by $514 \mathrm{sqkm}$.

Bare surface soil increase from 1986 to 1996 and continue to increase in 2006 and decline in 2016.

Water surface area decline between 1986 to 1996 by 1054sqkm and continue to decline in 2006 by $15298 \mathrm{sqkm}$ and continue to decline in 2016 by $1576 \mathrm{sqkm}$ 


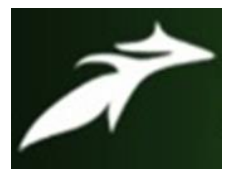

Gadona Enoch Alhamdu et al, International Journal of Advances in Agricultural Science and Technology,

Vol.7 Issue.11, November-2020, pg. 112-122

ISSN: 2348-1358

Impact Factor: 6.057

NAAS Rating: 3.77

\section{Degraded Areas in Mubi/North and Gombi local government areas}

The immediate causes of land degradation are inappropriate land use that leads to degradation of soil water and vegetation loss of both soil and vegetation biological diversity affecting ecosystem structure and functions Snel and Bot (2003).Land degradation was assessed in the first instance using remotely sensed data and GIS tools for processing and analyzing the degraded areas..

In Mubi/North and Gombi, the data presented in tables 2 and 4 shows the level of degradation that has occurred within the study periods. Human activities (anthropogenic) greatly affected the vegetation cover, massive expansion of agricultural land in Mubi/North between 1986 to 1996. Clearing vegetation cover increased by 730 hecters. For agriculture, while vegetation cover continued to depleted by 2050 hects. Urban expansion was on the increase as a result of population growth thus affecting vegetation cover by 3313hects from 1986 to 1996, 1815hects from 2006 to 2016, both Mubi/North and Gombi, have recorded decrease in vegetation cover because of the increase in agricultural lands and urban expansion; thus exposing vegetation cover to erosion, water surface areas were decreasing as a result there is increase in bare surface areas. Thus a sign of degradation of land. Most of the land is left bare during the dry season, thus exposing the soil to wind erosion.

Considering fluctuation in the trend of some of the land use within the period of study is partly ascribed to climatic factors( rainfall, temperature and others) the results showed that built up areas show upward trend, the upward trend is as a result of population growth and conversion of land use to build up areas.

The extent of degradation in the area, result obtained showed that the bare surface area and water bodies, the decrease in water surface and increase in bare surface areas shows that degradation is taking place.

The study thus recommend that, protective measures should be put in place to curtail indiscriminate cutting down of trees, fuel for wood and tree planting should be encouraged. Also there should have improved information on demographic data, climatic conditions and other related information for land managers for proper planning. 


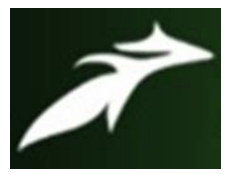

Gadona Enoch Alhamdu et al, International Journal of Advances in Agricultural Science and Technology,

Vol.7 Issue.11, November-2020, pg. 112-122

ISSN: 2348-1358

Impact Factor: 6.057

NAAS Rating: 3.77

\section{References}

[1]. Ann,V.D (2010) Soil Degradation: International Center for Erotology, University Gent.

[2]. Castelli,V; Elvidger,D.C; Li,C and Turek J.J (1998) Classifications-Base change: Theory and Applications to NALC Data Set, In: Lunetta,S.R and Elvidge (eds) (1998). Remote Sensing Change Detection, Environmental Monitoring Methods and Applications, U.S.A Ann Arber press.

[3]. Ezeomedu,I.C (2006) Change Analysis of Land use Land cover of Yola Metropolis to aid Planning for Sustainable Development. Unpublished B.Tech project submitted to the department of surveying and geoinformatics MAUTECH-Yola.

[4]. Food and Agricultural Organization (FAO) (2003) State of the world's Forest: Rome: Food and Agricultural Organization of the United Nations.

[5]. Farooq A;Quratul and F. Kashif.S (2014) Land Degradation Pattern Using GeoInformation Technology for KOT Addu,Punjab Province,Pakistan. Global journal of human social science; Geography, Geo-Sciences and Environment 13(1) 231-245.

[6]. Keijo,K and Kaoru, F (2012) Land use Land Cover Mapping Using a Gradable Classification Method, Remote Sensing ISSN 2072-4292 www,mdpi,com/journal/remote sensing. Accessed on 17/3/2017.

[7]. Lu,D and Wing,O (2005) Urban Classification using Full Spectral Information of Landsat ETM+Emagery.photogrametric engineering and remote sensing 71,1275-1284

[8]. Lillesand,T.M;Kiefer,R.N and Chipman J.W(2006) Remote Sensing and Image Interpretations 6 edition, John Wiley, New York.

[9]. Million,B (2002) The Status of National Forest in South Western Ethiopia.(first draft) ministry of Agriculture Addis Abba Ethiopia.

[10].Ndukwe, N.K(1997) Principle of Environmental Remote Sensing and PhotoInterpretation. New Concept Publishers, Enugu.

[11].Parakasam,C(2010) Land use Land cover Detection through Remote Sensing Approach. A case study of Kodiakanal Alux. Tomilandu: international journal of geomantic and geosciences2.122-167.

[12].Snel,M and Bot A (2003) Draft paper, Suggested indicators for land Degradation. Assessment of Dry Lands; FAO.Rome.

[13].Sirmanta,G and Mopriya, R (2012) Land use Land cover Classification of Urban Areas. A case study of Bundwn Municipality; India: international journal of Geometrics and Geoscience 2(1):234-254. 